https://www.journal-imab-bg.org

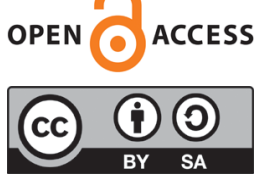

Original article

\title{
DERMATOGLYPHIC METHODOLOGY FOR ESTABLISHING ZYGOSITY IN THE TWINS
}

\author{
Ivan Maslarski1, Galina Yaneva ${ }^{2}$ \\ 1) Department of Anatomy, histology, pathology and forensic medicine, Medical \\ Faculty, University of Sofia, Bulgaria. \\ 2) Department of Biology, Faculty of Pharmacy, Medical University, Varna, \\ Bulgaria.
}

\begin{abstract}
Dermatoglyphic traits (DT) of the palms are an instrument, which is used in anatomy, anthropology, genetics and forensic services. DT can also be applied to medicine and in parts to the prevention of diseases, early diagnostic and establishing important characteristics about life.

The principal purpose of this study is to establish a dermatoglyphic instrument, which can help to establish the zygosity of twins via experimentation with different quantitative and qualitative dermatoglyphic indicators. The materials for investigation (or the sites of investigation) are finger and palm prints from both hands of 21 couple of monozygotic twins (MT) and 22 couples of dizygotic twins.

From the experiment, we can conclude that it is well worth the effort to do a prescription of key parameters, which direct the attention of doctors and anthropologist on the dermatoglyphic traits, which have regards towards zygosity. This paper presents a cheap and reliable method for establishing zygosity, via an algorithm from dermatoglyphic indicators in combination with blood group analysis.
\end{abstract}

Keywords: twin zygosity, twin method, Dermatoglyphic indicators,

\section{INTRODUCTION}

Dermatoglyphic traits (DT) of the palms are an instrument, which is used in anatomy, anthropology, genetics and forensic services. DT can also be applied to medicine and in parts to the prevention of diseases, early diagnostic and establishing important characteristics about life.

There are investigations in the sphere of "diagnostics methods for cancer of the mammary gland, schizophrenia, breast cancer and many other diseases $[1,2]$. There is an interest in the so-called twin method. The analysis done by foreign researchers under the current issue shows that twins are studied in a versatile method for morphological and functional characteristics. One part of the "Twin method" includes dermatoglyphic analysis. This analysis uses qualitative and quantitative variables. Using qualitative indicators, it has been established that palm prints fall under polygenic inheriting factors. Whereas, quantitative indicators of the palm prints are dermatoglyphic indicators, which all for the opportunity to investigate descendence and similarities.

Literature review shows that twin studies are not that frequent, one reason being challenges of obtaining anthropological material. Most of the twin studies study the physical development and reasons for multiple pregnancies [3]. Chen Lin Chang and Imaizumi have made multiple studies of the age influence and the consistency of multiple pregnancies. They concluded that there is a greater frequency of multiple pregnancies as the age increases. The influence of estrogen hormones and bromocriptine, as well as the division of the frequency of encountering 2, 3, 4 twins in certain age groups [4]. The influence of abortions and contraceptive medicine on the birth of twins. Nowadays the noninvasive prenatal determination of the twin zygosity by maternal plasma (DNA fragments) are giving opportunity to detect the zygosity and to compare it with the dermatoglyphic traits of the twins. [5]

However, the main aim of the investigation is to establish a dermatoglyphic instrument, that would help establish the zygosity of twins, via experimenting with different quantitative and qualitative dermatoglyphic indicators.

\section{MATERIALS AND METHODS}

This study uses dermatoglyphic methods, such as dactyloscopy - finger papillary images and a quantitative number of palm ridges [6], palmoscopy - palm images over the hypothenar, thenar, main palm lines, angles and, adt and dat [6], analysis of relationships between the zygosity and the order of twin birth. The model type of papillary fingerprints is determined using the indices of Dankmeijer (A/Wx100) and Furuhata(W/Lx100), whereas the intensity of the model via the delta index $(\mathrm{D} 110)=(\mathrm{L}+2 \mathrm{~W}) / 10$.

The ridge number is quantified via counting of the ridges, which cross or touch the line of Galton, that joins the central point of the triradius with the centre of the corresponding image (or concerned) image.

The principal purpose of this study is to establish a dermatoglyphic instrument, which can help to establish the zygosity of twins via experimentation with different quantitative and qualitative dermatoglyphic indicators. The materials for investigation (or the sites of investigation) are finger and palm prints from both hands of 21 couple of monozygotic twins (MT) and 22 couples of dizygotic twins.

The finger and palms prints have been received by the standard method. The fingerprinting was done by cov- 
ering the palm part surface of the hand with topographical ink, glass plate and a roller. The palm printing process was carried out by the standard way, meaning all moves related to the printing was helped by the investigator. A rotating device was used, by starting from one finger on the right hand and finishing with the 5th finger on the right hand. The palm surface was spread with topographical ink, the palm print was recorded after the coated palm was placed on a white sheet of paper. The white paper was placed on a convex cylindrical surface. This method ensures a complete printing of the palm surface, including the central part of the palm.

The diagnostics of the dermatoglyphic investigations were carried out with the help of binocular magnifying glass.

\section{RESULTS}

The results can be placed in two groups - qualitative and quantitative. In relation to the qualitative, it was established that fingerprints give an advantage above the loop (L), a significant percent comes from the monozygotic twins, $62.27 \%$ vs $52.37 \%$ in DT. Radial loops occur in MT $3.18 \%$, whereas in DT $1.43 \%$. In relation to the distribution of the loops, it was concluded that there is a prevalence of loos of the 5th finder; $87.5 \%$ in MT and $69.04 \%$ with DT. Whorls (W) of the fingerprints were 29.77 in MT vs $40.47 \%$ in MT. In relation to the main palm line; line D it was an observed deviation in the method of finishing in MT and DT. The finishing of the main palm lines in twins is displayed in a table form [table 1]. The frequency of axial triradius is shown in a separate table [table 2] [7].

Table 1. Types of major palm lines and Cummins index

\begin{tabular}{|c|c|c|c|c|c|c|c|}
\hline \multirow{2}{*}{\multicolumn{2}{|c|}{ Types of major palm lines }} & \multicolumn{3}{|c|}{ Monozygotic twins (MZ) } & \multicolumn{3}{|c|}{ Dizygotic twins(DZ) } \\
\hline & & $\begin{array}{l}\text { Left hand } \\
\mathrm{n}=44\end{array}$ & $\begin{array}{l}\text { Right hand } \\
\mathrm{n}=44\end{array}$ & $\begin{array}{l}\text { Both hands } \\
\mathrm{n}=88\end{array}$ & $\begin{array}{l}\text { Left hand } \\
\mathrm{n}=44\end{array}$ & $\begin{array}{l}\text { Right hand } \\
\mathrm{n}=44\end{array}$ & $\begin{array}{l}\text { Both hands } \\
\mathrm{n}=88\end{array}$ \\
\hline \multicolumn{8}{|l|}{$\mathbf{A}$} \\
\hline \multirow[t]{2}{*}{$1(+2)$} & value & 6 & 4 & & 4 & 0 & \\
\hline & $\%$ & 13,63 & 9,09 & 11,36 & 9,5 & - & 4,7 \\
\hline \multirow[t]{2}{*}{$3(+4)$} & value & 28 & 36 & & 32 & 33 & \\
\hline & $\%$ & 63,7 & 81,8 & 72,72 & 76,2 & 78,6 & 77,38 \\
\hline \multirow[t]{2}{*}{$5^{6}\left(+5^{6}+6\right.$} & value & 26 & 5 & & 5 & 7 & \\
\hline & $\%$ & 13,63 & 11,36 & 12,54 & 11,9 & 16,6 & 14,28 \\
\hline \multicolumn{8}{|l|}{$\mathbf{D}$} \\
\hline \multirow[t]{2}{*}{$7(+8+x+0)$} & value & 4 & 6 & & 8 & 8 & \\
\hline & $\%$ & 9,09 & 13,63 & 11,36 & 19,04 & 19,04 & 19,04 \\
\hline \multirow[t]{2}{*}{$9(+10)$} & value & 24 & 7 & & 23 & 13 & \\
\hline & $\%$ & 54,54 & 15,9 & 35,22 & 54,76 & 30,95 & 42,85 \\
\hline \multirow[t]{2}{*}{$11(+12+13)$} & value & 18 & 33 & & 8 & 18 & \\
\hline & $\%$ & 40,9 & 75 & 57,95 & 19,04 & 42,85 & 30,95 \\
\hline \multirow{2}{*}{$\begin{array}{l}\text { Cummins' } \\
\text { index }\end{array}$} & A & 3,04 & 3,77 & 3,41 & 3,28 & 3,71 & 3,5 \\
\hline & $\mathrm{D}$ & 2,75 & 5,48 & 4,11 & 3,78 & 4,28 & 4,03 \\
\hline
\end{tabular}

Table 2. Axial triradii

\begin{tabular}{|l|l|l|l|l|l|l|l|}
\hline \multicolumn{2}{|c|}{} & \multicolumn{2}{c|}{ MZ } & \multicolumn{3}{c|}{ DZ } \\
\cline { 3 - 8 } \multicolumn{2}{|c|}{} & $\begin{array}{l}\text { Left hand } \\
\mathrm{n}=44\end{array}$ & $\begin{array}{l}\text { Right hand } \\
\mathrm{n}=44\end{array}$ & $\begin{array}{l}\text { Both hands } \\
\mathrm{n}=88\end{array}$ & $\begin{array}{l}\text { Left hand } \\
\mathrm{n}=42\end{array}$ & $\begin{array}{l}\text { Right hand } \\
\mathrm{n}=42\end{array}$ & $\begin{array}{l}\text { Both hands } \\
\mathrm{n}=84\end{array}$ \\
\hline \multirow{2}{*}{$\mathrm{t}$} & value & 9 & 12 & & 14 & 14 & \\
\cline { 2 - 8 } & $\%$ & 20.45 & 27.27 & 23.86 & 33.33 & 33.33 & 33.33 \\
\hline \multirow{2}{*}{ t' } & value & 19 & 23 & & 19 & 20 & \\
\cline { 2 - 8 } & $\%$ & 43.18 & 52.27 & 47.72 & 45.24 & 47.62 & 46.42 \\
\hline \multirow{2}{*}{ t" } & value & 4 & 5 & & 3 & 2 & \\
\cline { 2 - 8 } & $\%$ & 9.1 & 11.36 & 10.28 & 7.14 & 4.76 & 5.95 \\
\hline \multirow{2}{*}{ tt" } & value & 2 & 1 & & 2 & 2 & \\
\cline { 2 - 8 } & $\%$ & 5.45 & 2.27 & 3.40 & 4.76 & 4.76 & 4.76 \\
\hline
\end{tabular}




\begin{tabular}{|c|c|c|c|c|c|c|c|}
\hline \multirow[t]{2}{*}{$t^{\prime} t^{\prime \prime}$} & value & 1 & 0 & & & & \\
\hline & $\%$ & 2.27 & - & 1.13 & & & \\
\hline \multirow[t]{2}{*}{ tt't" } & value & 2 & 0 & & 1 & 0 & \\
\hline & $\%$ & 4.54 & - & 2.27 & 2.38 & - & 1.19 \\
\hline \multirow[t]{2}{*}{$\mathrm{tt}$} & value & & & & & & \\
\hline & $\%$ & & & & & & \\
\hline \multirow[t]{2}{*}{$t^{\prime} t^{\prime}$} & value & 2 & 0 & & & & \\
\hline & $\%$ & 4.54 & - & 2.27 & & & \\
\hline \multirow[t]{2}{*}{0} & value & & & & & & \\
\hline & $\%$ & 6.81 & 6.81 & 6.81 & & & \\
\hline
\end{tabular}

In summary, the quantitative indicators made via parametrical and unparametrical methods, that show a correlation (link) with zygosity, (in relation to) the left and right hand are as follows: five indicators of the left-hand $\Sigma$ RT I -V sin, RTI sin, RT III sin, RT $1-\mathrm{V} \sin , \mathrm{RT} \mathrm{V} \sin$, five indicators of the right hand $\Sigma \mathrm{RT} \mathrm{I}-\mathrm{V}$ dex, $\Sigma$ RT d-a dex, RT b-a dex, RTII dex, RT I-V dex and two total indicators TRC a-d, TRC I-V.

\section{DISCUSSION:}

According to the twin method during development, every characteristic is completely dependent on inheritance as well as the surrounding environment. Every individual has a certain genotype. This genotype determines the range, in which the genotypes can develop, whereas the resulting phenotype will develop based on the external factors that development takes place.

The assignment of the twin method is establishing the correlative role of inheritance factors and the factors of the environment in the variability of different characteristics. In other words, to what extent the variations of characteristics play a role among individuals is dependent on the genetic differences and changes in the external environment. This method is used in the field of medicine during the study of inherent predisposition to different diseases, for example: Down's Syndrome, Cerebral gigantism, Diabetes, Schizophrenia, Chromosomal anomalies and others $[8,9]$.

The essence of the Twin method is concluded with the putting together the differences among internal pair differences in MTand DT along the way of "similarity method", in the base that introduces the genetic uniformity in MT. The stage in which the variation is dependent on the genetic differences, the determination of the inheritance can be calculated.

When establishing the zygosity of twins, the loops play a role and more specifically than the ulnar loops of the fifth finger with MT. In the radial loops their presence in the second finder of MT. The loops are a phenomenon with MT, but a characterise for DT, especially for the 4th finger. In DT, the whorl is well expressed in the 5th finger. The main palm lines have a stance with the ending of line D. In MT is observed completion of field 11 of the right hand, this is distinctive in over $75 \%$ of the cases. In the dizygotic twins, this completion is common in field 9. Ridges triradiialong the palm show a significant difference, as the t't variant, and lack of triradius occurs only in MT.

\section{CONCLUSION}

Characterising the zygosity via the twin method has a great significance for the Twin method. This method is applied in the study of inheritance in the fields of anatomy, medicine, genetics, anthropology and criminology. From the Inheritance experiment, we conclude that it is well worth establishing predispositions for key parameters, that direct the attention of physician and anthropologist towards these papillary representations. These representations have a stance towards zygosity. We must also note that qualitative parameters have a greater stance on zygosity, in which there are greater differences between MT and DT.

We propose the following algorithm from the Dermatoglyphics indicators that have a stance of zygosity. The profile of MT; which responds to the following indicators: the presence of ulnar loops of the fifth finger, absence of spiral or if present its located on the fourth finger, loops prevailing along the fingers of the right hand, presence of combined t't or complete absence of palm triradius. Main plam line D that ends in 11th or 12th field of the right hand

Dermatoglyphic indicators are an interesting and fast variant of establishing zygosity but must be combined with a blood group analysis. This article aims to direct future investigators towards the described parameters and introduce an algorithm for determining zygosity. As there is a need for future investigation in this field. 


\section{REFERENCES:}

1. Yaneva G, Dimitrova T, 127-35. [PubMed] Cherneva D, Ivanova N, Fialkovska N, Vachkov I, et al. Quantitative dermatoglyphic study of the finger ridge count in breast carcinoma patients from Northeastern Bulgaria. Scripta Scientifica Salutis Publicae. 2018 May (4):51-55.

2. Yaneva G, Ingilizova G. Main line patterns of palmar dermatoglyphics in female breast cancer patients. MOJ Anat \& Physiol. 2018; 5(6):345347. [Crossref]

3. Bertranpetit J, Marin A. Demographic parameters and twinning: a study in Catalonia, Spain. Acta Genet Med Gemellol (Roma). 1988; 37(2):
4. Imaizumi Y. Infant mortality rates in single, twin and triplet births, and influencing factors in Japan, 1995-98. Paediatr Perinat Epidemiol. 2001 Oct;15(4):346-51. [PubMed]

5. Qu JZZ, Leung TY, Jiang P, Liao GJW, Cheng YKY, Sun H, et al. Noninvasive prenatal determination of twin zygosity by maternal plasma DNA analysis. Clin Chem. 2013 Feb; 59(2):427-35. [PubMed] [Crossref]

6. Cummins H, Midlo C. Finger prints, palms and soles: An introduction to dermatoglyphics. Dover Publications. January 1, 1961.
7. Maslarski I, Belenska L. The papillary images as part of the twin method. Acta Morphol Anthropol. 2015; 22:8896. [Internet]

8. Asen D. Secrets in Fingerprints: Clinical Ambitions and Uncertainty in Dermatoglyphics. CMAJ. 2018 May 14;190(19):E597-E599. [PubMed] [Crossref]

9. Fournier NA, Ross AH. Sex, Ancestral, and Pattern Type Variation of Fingerprint Minutiae: A Forensic Perspective on Anthropological Dermatoglyphics. Am J Phys Anthropol. 2016 Aug;160(4):625-32. [PubMed] [Crossref]

Please cite this article as: Maslarski I, Yaneva G. Dermatoglyphic methodology for establishing zygosity in the twins. $J$ of IMAB. 2020 Jul-Sep;26(3):3313-3316. DOI: https://doi.org/10.5272/jimab.2020263.3313

Received: 09/06/2019; Published online: 17/09/2020

\section{Address for correspondence:}

Assoc. Prof. Ivan Maslarski, Ph.D.

Chairman Dept. Anatomy, Histology, Pathology and Forensic medicine, Faculty of Medicine, University of Sofia, Bulgaria

E-mail: maslarsky@gmail.com 